... y feminismo / and feminism

\title{
UNA HISTORIA PARTICULAR DE LA MÚSICA: LA CONTRIBUCIÓN DE LAS MUJERES ${ }^{1}$
}

Pilar Ramos López

Universidad de La Rioja

\begin{abstract}
RESUMEN: Las publicaciones sobre la historia de las mujeres se han asumido con tanta normalidad que muchos investigadores obvian cuestionarse si su objeto de estudio requiere alguna preparación o tratamiento especial. Como resultado los trabajos musicológicos a menudo dan por sentado que las mujeres desarrollaron sus actividades musicales en las mismas condiciones que sus colegas masculinos, lo cual no era el caso hasta fechas bastante recientes. El artículo incide sobre la necesidad de un conocimiento de la historia de las mujeres que permita valorar las fuentes y los datos disponibles sobre sus actividades musicales, trascendiendo la anécdota. Una de las principales diferencias entre las carreras de los compositores y las trayectorias femeninas es la profesionalidad. Este artículo estudia algunas de las implicaciones para la historiografía de esta problemática profesionalidad de la actividad musical de las mujeres antes de 1900.
\end{abstract}

Palabras clave: Mujeres, música, profesión musical, diferencia, historiografía.

\section{A PARTICULAR MUSIC HISTORY: THE CONTRIBUTION OF WOMEN}

ABSTRACT: Researches on women history are so common today that many scholars overlook to think about any special qualification or approach their topic

1. Diferentes versiones preliminares de este artículo se han leído como conferencias en la Facultad de Filosofía y Letras de Granada, la Residència d'investigadors del CSIC en Barcelona, y la Associació Valenciana de la Música en Carcaixent entre marzo de 2012 y marzo de 2013. Mi agradecimiento por su invitación a los profesores Aurora López, María Gembero Ustárroz, y Ramón Canut. 
might require. As a result, in musicological studies women are often supposed to have carried on their musical activities under the same circumstances as their coeval men, which was not the case till recent times. This paper highlights the necessity of knowing the history of women in order to value the available sources and data on their musical activities, so that we can go beyond the anecdote. One of the main differences between male composer's professional career and women's is professionalism. This paper studies some of the consequences for historiography of the problematical professionalism of women's musical activity before 1900 .

Keywords: Women, music, musical professionalism, historiography, difference.

\section{Introducción}

El interés por la historia de las mujeres ha surtido nuestras tiendas de música, salas de concierto y librerías, sean locales o virtuales, de composiciones, interpretaciones y estudios. Estudiar las mujeres en la historia de la música no es ya una corriente novedosa, ni tampoco una moda. Por el contrario, las publicaciones sobre mujeres se han asumido con tanta normalidad que muchos investigadores obvian cuestionarse si su objeto de estudio requiere alguna preparación o tratamiento especial. Cabe, no obstante, preguntarse ¿es diferente investigar sobre las mujeres en la historia de la música?

Si por "historia de la música" entendemos la historia de la composición en cuanto estructura musical, entonces probablemente concluyamos que es indiferente quién sea el autor. De hecho, algún experimento indica la imposibilidad de diferenciar entre composiciones escritas por varones o por mujeres ${ }^{2}$. Sin embargo, una historia de la música concebida exclusivamente como historia de la composición, y en concreto, como historia de los estilos y las formas musicales, tiene escasa utilidad para quien no desee componer o tocar, pues nos informa poco acerca de las funciones, significados, valores, y usos de la música. En otras palabras, una historia cultural o social de la música no puede limitarse a ser una historia de la composición. Volviendo pues a nuestra pregunta inicial, estudiar las actividades musicales de las mujeres sí es diferente, tiene implicaciones que con demasiada frecuencia pasan desapercibidas no solo para los historiadores de la música, sino también para investigadores de las Ilamadas ciencias humanas, y para el común de la gente.

2. Se dividió a los compositores en tres grupos: adolescentes, jóvenes y maduros, cuyas piezas fueron analizadas por profesores de composición experimentados. No fue posible diferenciar entre las piezas de los varones y las de las mujeres en ninguna de las franjas de edad. Hassler, M. "Biologia e creatività", en Enciclopedia della musica. J.-J. Nattiez (dir.). Torino, Giulio Einaudi, Vol. II, 1999, pp. 271-287. 
Mi propósito es tratar esas implicaciones específicas de la actividad musical de las mujeres. Me referiré a las diferencias que estimo más relevantes en relación a la historia de la música occidental. No obstante, es interesante añadir que la especificidad ligada a la división de las actividades musicales entre hombres y mujeres se da también en otras culturas ${ }^{3}$. En realidad, hablar de una historia de lo particular no es una novedad. Por el contrario, es un lugar común definir la historia frente a la ciencia de lo universal (la matemática o la física) como la narración de algo que ha ocurrido una vez y por tanto, no es repetible en las mismas condiciones. Por otra parte, el hombre universal, abstracto, al que se referían los libros de historia hasta hace unas décadas, es una invención no solo occidental, sino reciente ${ }^{4}$. Así, las constituciones liberales y conservadoras de finales del XVIII y del siglo XIX consideraban como 'hombres', 'personas', 'gente' o 'pueblo' solo a los varones blancos libres. Nada más lejos de la idea de hombre universal.

De manera paralela, la igualdad de talento o capacidad entre los hombres y las mujeres (no en el sentido de identidad, ni de indiferenciación, sino en el de equidad) es una idea ajena a algunas épocas históricas, si bien la han defendido desde hace siglos tanto hombres como mujeres. No obstante, incluso para quienes reivindicaban las capacidades y talentos femeninos, como Christine de Pisan (s. XIV-XV), o Cornelius Agrippa de Nettesheim (s. XVI), resultaba evidente que sus condiciones y posibilidades de desarrollo eran muy distintas.

Conscientes de la injusta exclusión de las mujeres, libros actuales de historia de la música parecen asumir que si a las historias tradicionales, en las que solo se nos hablaba de compositores, se añaden unas cuantas compositoras, se cumple con lo políticamente correcto. Es una tendencia resumida en la expre-

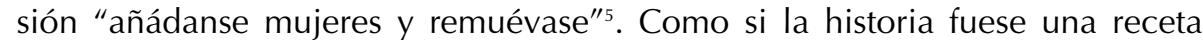
cuyo proceso o resultado apenas variase por la adición de otro ingrediente. Sucedió por ejemplo en la historia de la música escrita por Donald J. Grout y revisada por Claude V. Palisca, cuya edición de 1996 (la quinta) incluyó a Hildegard von Bingen, Beatriz de Dia, Elizabeth Jacquet de la Guerre, Clara Wieck Schumann, Ruth Crawford Seeger y Sofia Gubaidulina, sin modificar la estructura anterior (la de la cuarta edición, de 1988) ${ }^{6}$. Por el contrario, uno de los objetivos de este breve artículo es incidir en que el proceso cambia si nos ocu-

3. Sarkissian, M. "Gender and Music", en H. Myers (ed.), Ethnomusicology. An introduction. London, 1992, pp. 337-348, p. 338.

4. Varios estudios han insistido en cómo Kant y los filósofos ilustrados excluían a las mujeres como sujeto ético y político. Véase por ejemplo el capítulo VI "De usos y abusos de las abstracciones", en C. Amorós, Tiempo de feminismo. Sobre feminismo, proyecto ilustrado postmodernidad. Madrid, Cátedra, 1997, pp. 261-302.

5. Wiesner, M-E. Women and Gender in Early Modern Europe. Cambridge, Cambridge University Press, 1993, p. 4.

6. Grout, D. J. y Palisca C. V. A History of Western Music. New York, Norton, 1988 y 1996. 
pamos de las mujeres porque el estudio de las mujeres tiene unas dificultades específicas, y en la medida en que cambia el proceso, cambia también el resultado. Por ejemplo, incluir a Hildegard von Bingen supone integrar repertorios locales en una historia general de la música, sobrepasando los objetivos del difundido manual de Grout y Palisca. Integrar a las mujeres implica, pues, repensar la estructura, el centro y los márgenes, lo avanzado y lo retrógrado, la vanguardia y lo académico, lo privado y lo público.

Si nos planteamos una historia de la música que, más allá de mencionar puntualmente algunas compositoras o intérpretes, estudie también las mecenas, las difusoras y las consumidoras de música, entonces, tendremos que detenernos a pensar cómo algunos acontecimientos históricos han supuesto una repercusión diferente para las mujeres, y por ello hemos de considerarlos de una manera menos uniforme.

1. Pensemos, por ejemplo, en 1492, un año clave, y en sus consecuencias para la ciudad europea más ligada al Nuevo Mundo en las décadas siguientes: Sevilla. Para las sevillanas, que viajaron durante el siglo XVI mucho menos que sus paisanos varones a América, el 'Descubrimiento' (o Encuentro, si se prefiere) significó ante todo el asumir una mayor capacidad de acción en el comercio, la artesanía, el campo, e incluso en el ámbito doméstico, donde la ausencia del padre, marido o hijos adultos les otorgaba una autoridad nueva, provocando una serie de conflictos estudiados en el precioso libro de Mary Elizabeth Perry Ni espada rota ni mujer que trota (1993).

Dictada en el mismo año, 1492, la prohibición del judaísmo en los reinos castellano y aragonés tuvo repercusiones muy distintas para los hombres y para las mujeres en tanto que trastocó la división tradicional de actividades religiosas entre los sexos. Los documentos inquisitoriales muestran que, una vez prohibidos los libros y el culto judío, las mujeres se erigieron en las principales guardianas y transmisoras no ya de la religión sino de la cultura hebrea, en la medida en que la obediencia a los numerosos preceptos religiosos solo podía realizarse a escondidas en el ámbito privado ${ }^{7}$.

2. Podemos ver otro ejemplo en la situación vivida en las orquestas tras el reclutamiento de soldados durante las dos guerras mundiales. Las norteamericanas accedieron entonces a puestos en las orquestas clásicas y de jazz. Por ello fueron relevantes en el desarrollo del estilo swing de los años $40^{\circ}$. Pero una vez regresados los hombres del frente, volvieron a desbancar a las instrumentistas. El mismo proceso se generalizó en muchos

7. Melammed, R. L. Heretics or Daughters of Israel? The Crypto-Jewish Women of Castle. New York, Oxford University Press, 1999.

8. Tucker, S. Swing Shift: "All-Girl" Bands of the 1940s. Durham, Duke University Press, 2000. 
sectores profesionales. De manera que, para facilitar la vuelta de las mujeres a sus hogares (necesaria para la reincorporación de los soldados a sus empleos civiles), se creó la ola de propaganda del todo hecho en casa, de mermeladas, bizcochos, comida casera, peinados con permanentes imposibles y obsesión por el cuidado personal de los hijos, fenómeno que Betty Friedan (1921-2006) llamó 'mística de la feminidad'.

Las diferencias en la repercusión de acontecimientos históricos para los varones y las mujeres hacen que en el estudio de las mujeres se revele especialmente la falacia de la historia como una narrativa de progreso ininterrumpido en una única dirección. Siempre hay discontinuidades, retrocesos, recesos, vías paralelas o divergentes. Hace solo unos años explicar esta idea llevaba tiempo en las clases. Por desgracia, hoy en día todos sabemos que el retroceso en derechos y libertades es no solo posible, sino cotidiano.

La particularidad de la historia de las mujeres, los ritmos propios, obligan al historiador alerta a estar al tanto de las investigaciones realizadas en ese campo, aunque no sea ésta su área de interés. Por ejemplo, varios textos escritos con motivo del centenario de Tomás Luis de Victoria (1548-1611) han seguido manteniendo la visión del retiro del compositor en las Descalzas Reales de Madrid como una muestra de su beatífico carácter. Pero nadie en busca de recogimiento hubiese escogido el monasterio donde, como ha demostrado Magdalena Sánchez ${ }^{10}$, se concentraban asiduamente tantos reyes, políticos e intrigas, gestando gran parte de la política internacional del reino. Es más, contados puestos europeos de su tiempo ofrecían una vida tan regalada a un músico. En otras palabras, es necesario leer también lo que se escribe sobre historia de las mujeres, porque ellas no fueron espectadoras de un drama protagonizado por varones. Ellas participaban en el drama.

Durante los años de surgimiento de la musicología como disciplina académica y 'ciencia del espíritu', el último cuarto del XIX y primeros años del XX, los historiadores fueron reacios a hablar de las mujeres. Esta voluntad de ignorar a las mujeres como sujeto histórico no era casualidad. Las mujeres accedían entonces a empleos en la industria y los servicios de una forma que se consideró masiva, suscitando entre sus compañeros un rechazo similar al que provoca hoy la inmigración entre muchos trabajadores de cualquier sexo y país. La paralela reivindicación femenina de derechos legales (voto, divorcio, custodia de los hijos, etc.) fue contestada no solo policialmente, sino también en la academia. Los científicos se hallaban en esos años involucrados en las teorías que asimilaban a las mujeres con los niños y con las razas 'inferiores', mientras los artistas y los novelistas se recrea-

9. Friedan, B. The Feminine Mystique. New York, Norton, 1963.

10. Sánchez, M. S. The empress, the queen, and the nun: women and power at the court of Philip III of Spain. Baltimore, Johns Hopkins University Press, 1998. 
ban en féminas lánguidas, enfermizas o histéricas. Eran Ídolos de la perversidad, en lúcida expresión de Briam Dijkstra" ${ }^{11}$. Los estudios universitarios eran casi inaccesibles para las mujeres ${ }^{12}$. Al mismo tiempo, los historiadores escribían muy poco sobre ellas. En la época del historicismo, cuando se creía que el origen determinaba la evolución posterior, un pasado sin mujeres dignas de reseñar justificaba el rechazo a las reivindicaciones femeninas de aquel presente. Por ello se difundió una imagen de otras épocas históricas en la que las mujeres estaban más ausentes de lo que las fuentes y los estudios anteriores permitían suponer.

Es decir, la idea, tan extendida hoy, de que las mujeres no han aparecido hasta hace unas décadas en los libros de historia es falsa. Por ejemplo, una de las primeras historias del arte, las Vidas de Giorgio Vasari (1550 y 1568), menciona varias pintoras, mientras que Ernest Gombrich no nombra a ninguna en su Historia del arte (1950) -un libro que ha marcado a generaciones de historiadores-. La misma comparación podríamos establecer entre Nicolás Antonio (1617-1684), quien incluye una relación de escritoras en su Biblioteca Hispania Nova [1684?] ${ }^{13}$, y tantas historias de la literatura española publicadas en el siglo XX. En definitiva, no podemos construir historias teleológicas de liberación de la mujer, en primer lugar porque la historia no ha sido teleológica, por lo menos desde el punto de vista social. Y en segundo lugar, porque ese concepto de liberación ha significado cosas diferentes según las épocas y los espacios, lo mismo que también sucede hoy.

La falacia del progreso continuo de las mujeres es pues otra especificidad que con frecuencia olvidamos. No es que los varones hayan conocido un progreso continuo, sino que los ritmos y las repercusiones de las discontinuidades, avances, o retrocesos han sido en ocasiones divergentes para los varones y para las mujeres en unas mismas coordenadas temporales y espaciales. Por ello las historias de las mujeres han propuesto otras periodizaciones, tal y como habían hecho historiadores de la economía, la sociedad y la cultura, como Fernand Braudel.

\section{La profesionalidad como diferencia}

Cualquier investigador de la historia musical de las mujeres se encontrará con una de las principales diferencias entre las carreras masculinas y las trayectorias

11. Dijkstra, B. Idolos de la perversidad. La imagen de la mujer en la cultura de fin de siglo. Madrid, Debate, 1994.

12. Solo unos datos: la universidad de Berlín comenzó a admitir mujeres en 1908, Oxford y Cambridge permitían a las mujeres asistir a algunos colleges, pero no les concedió títulos hasta después de la I Guerra Mundial, y Cambridge no les dio el derecho a voto que normalmente acompañaba a los licenciados hasta 1948. Anderson, B. S. y Zinsser, J. A History of their own. Women in Europe from Prehistory to the Present. Vol. II. London, Penguin, 1988, p. 188.

13. Antonio, N. "Appendices ad Bibliothecam scriptorum hispaniae. Ginaeceum hispanae minervae sive de gentis nostrae feminis doctrina claris ad bibliothecam scriptorum" Biblioteca Hispania Nova [1684?] sive hispanorum scriptorum qui ab anno md ad mdclxxxiv floruere Madrid, 1996. Facsímil de Madrid, Viuda y Herederos Joachim de Ibarra, 1788, pp. 343-353. 
femeninas: la profesionalidad. Consideremos, por ejemplo, una compositora que sí podemos considerar profesional, Isabella Leonarda (1620-1704), cuya vida, sin embargo, guarda pocos paralelismos con la de sus colegas masculinos. ¿Qué monje de su talento musical se vio recluido en un convento 'de provincias' en la Italia de entonces? Un monje, además, si estaba ordenado podía decir misa (una fuente segura de ingresos de la que carecían las monjas), impartir clases fuera del monasterio, viajar, inspeccionar los órganos, y, en definitiva, relacionarse personalmente con otros músicos de una manera imposible para Isabella Leonarda. Es razonable pensar que este confinamiento redundó en una falta de originalidad en su obra, una característica que, por otra parte, comparten la mayoría de compositores varones de su tiempo. La originalidad, no era, recordémoslo, uno de los principales valores en la estética del XVII. En otras palabras, quizás el talento de Leonarda, desplegado en una veintena de volúmenes de música impresa, hubiera producido obras aún mejores en otro contexto ${ }^{14}$.

Pero ya lo hemos dicho: en la historia no hay leyes universales. El caso de Hildegarda de Bingen (1098-1179) parece apoyar el razonamiento contrario, la radical originalidad de su producción hubiera sido más difícil de haber sido ella varón (porque entonces hubiera sido reclamada para un centro más importante), e improbable fuera de los muros conventuales. Sin embargo, poco tenían en común los monasterios del siglo XII (Hildegarda) con los del siglo XVII (Isabella Leonarda). Por una parte, era distinto el tipo de clausura, obsesiva en la Europa católica después de Trento, (otra cosa fue el Nuevo Mundo), y más relajada en la Edad Media; y, por otra, en el siglo XVII los conventos no producían ya la mayor parte de la cultura escrita. En definitiva, las condiciones de Isabella fueron muy distintas a las de Hildegard, siendo ambas, como fueron, monjas con un talento musical excepcional.

Aunque muchos historiadores no se lo plantean al hablar de las compositoras, la profesionalidad sí era una cuestión relevante para ellas en los siglos XVIII y XIX. Así lo pensaba Félix Mendelssohn, cuando en una carta a su madre le exponía las razones que impedían a Fanny (1805-1847) desarrollar una carrera como compositora. Nadie podía discutirle talento o preparación musical, y menos aún Félix, que tanto se aprovechó de ambas cualidades de su hermana. Sin embargo, según el parecer de Félix, Fanny no podría construir una carrera, en el sentido de planificar sus publicaciones con la coherencia que exigía una dedicación exclusiva y de por vida, imposible para una mujer que en algún momento sería esposa y madre ${ }^{15}$.

14. Isabella Leonarda no pasó desapercibida para los sabios de la época, y así le alaba Sébastien de Brossard en su Catalogue des livres de musique, théorique et prattique, vocalle et instrumentalle (Manuscrito 1724); ed. Y. de Brossard (Paris, 1994).

15. Carta del 22-11-1836. Citada en Citron, M. "The Lieder of Fanny Mendelssohn Hensel". Musical Quaterly 69 (1983), p. 572. 
Ajeno al mundo de la composición, el filósofo y economista John Stuart Mill (1806-1873) fue muy consciente del problema de la profesionalidad cuando se trataba de valorar la aportación musical de las mujeres:

Es en las bellas artes, en el sentido estricto del término, donde parecen apreciarse a primera vista las pruebas más poderosa [sic] de la originalidad inferior de las mujeres, teniendo en cuenta que la opinión pública puede decirse que no les impide cultivar estas artes, sino que más bien las anima a ello, y que la educación de las mujeres, en vez de dejar de lado estas artes, se centra principalmente en su ejercicio, en las clases ricas. Sin embargo, en esta actividad han quedado más por debajo todavía que en muchas otras de los logros más eminentes de los hombres. No obstante, esta falta no necesita de más explicación que el hecho bien conocido, y de verdad más universal en las bellas artes que en ninguna otra cosa, de la gran superioridad de los profesionales sobre los aficionados. A las mujeres de las clases cultas se les enseña casi sin excepción, en mayor o menor grado, alguna rama de las bellas artes, pero no para que se puedan ganar con ella la vida ni la consideración social. Todas las artistas femeninas son aficionadas. Las excepciones son de las que confirman la verdad general. A las mujeres se les enseña música, pero no para que la compongan, solo para que la interpreten; en consecuencia, los hombres solo son superiores en música a las mujeres precisamente como compositores. La única de las bellas artes que practican las mujeres, en cierta medida, como profesión, y que ejercen durante toda su vida, es la representación teatral; y en esta se reconoce que son iguales a los hombres o incluso superiores. Para que la comparación fuera justa debería establecerse entre las obras de las mujeres en cualquier arte y las de los hombres que no practican esa [sic] arte como profesión. En la composición musical, por ejemplo, no cabe duda que las mujeres han producido obras tan buenas como las mejores de los músicos aficionados varones ${ }^{16}$.

Quizá resulte necesario apuntar que en la década de 1860 la inferioridad de las mujeres no era una opinión, sino una noción científica y médica, como también lo era la superioridad de la raza blanca. La situación jurídica de la mujer no era entonces equiparable a la del varón en ningún país europeo, como no lo ha sido hasta bien avanzado el siglo XX. Nadie esperaba de una mujer que se comportase como un hombre. $Y$ sin embargo, los historiadores escribimos sobre las mujeres como escribimos sobre los hombres, pensando que tienen una

16. Stuart Mill, J. El sometimiento de las mujeres (1869). Prólogo de Ana de Miguel. Madrid, Edaf, 2005, pp. 197-198. Se cree que en este libro están muy presentes ideas de su mujer, Harriet Taylor, fallecida en 1858. 
carrera profesional y unas circunstancias semejantes, algo que, como ya especificó Stuart Mill, no era el caso, al menos en el XIX.

En el año en que escribe Stuart Mill su ensayo, 1869, compone Pauline Viardot (1821-1910) su tercera ópera de cámara, Le dernier sorcier, cuyo libreto había escrito en francés Turnegev. Ella había estudiado composición con Anton Reicha en el Conservatorio de París (algo que muy pocas mujeres pudieron hacer en su época), y de manera privada con Chopin (quien aprobó los arreglos para voz y piano de sus mazurcas, cuyo éxito sería enorme). Sin embargo, Viardot no se consideraba compositora, sino cantante. Lo sabemos por una carta que escribió su marido, Louis Viardot, a la novelista George Sand, gran amiga de Pauline ${ }^{17}$.

El peligro sobre el cual nos advierte perspicazmente Stuart Mill, el de comparar cosas que no pueden medirse con el mismo rasero, la obra de aficionados con la obra de profesionales, con frecuencia se obvia en la historia Ilamada compensatoria. Este tipo de historia, muy común en la historiografía feminista de los años 80 y aún hoy en práctica, trata de suplir la ausencia de las mujeres en las historias de la música añadiendo nombres y obras de compositoras, intérpretes, mecenas, etc. Como las historias nacionalistas, las historias compensatorias recurren a la hipérbole y a la queja por el agravio del olvido, sin cuestionar los fundamentos, objetivos y criterios de su labor. Paradójicamente, aunque las historias compensatorias pretenden exhibir la diferencia, en realidad tienden a ocultarla, porque las peculiaridades, como, por ejemplo, la falta de profesionalidad, quedan desapercibidas entre tanto genio.

No obstante, Pauline Viardot era muy consciente de estas diferencias. En consecuencia restringió sus composiciones a los géneros que dominaba como intérprete: las canciones y las óperas salonnières (de salón, para voces y piano) y escribió poca música instrumental, sobre todo para piano (era una estupenda pianista, al decir de Liszt y de Chopin). Comparándola precisamente con Liszt (18111886) y con Chopin (1810-1849), ambos grandes instrumentistas que sí desarrollaron de manera deliberada una carrera de compositores, o con Gounod (1818-1893), quien había coincidido con ella en las clases de composición, no le hacemos, sin embargo, ningún favor a Pauline Viardot. Ella no vió ningún plus de prestigio o satisfacción en considerarse compositora. ¿Por qué iba a hacerlo? Eran los compositores, fuesen noveles o consagrados, franceses, alemanes o rusos,

17. "Pauline has not imagined herself to be a composer, she has written a fairly large number of pieces of music but always in accordance with the circumstances that presented themselves [...] But she is not enough of a composer, she cannot find to a sufficient extent within herself and without the aid of a particular circumstance, the musical ideas that are necessary to succeed in all topics". Zekulin, N. The Story of an Operetta: Le Dernier Sorcier. München, 1989, p. 72. Citado en Harris, R. M. The music salon of Pauline Viardot: featuring her salon opera Cendrillon. Tesis doctoral inédita. Louisiana State University and Agricultural and Mechanical College, 2005. p. 36. Disponible en: http://etd.Isu.edu/docs/available/etd-04082005-095548/unrestricted/Harris_dis.pdf. 
quienes corrían tras ella rogándole que cantase sus obras, dedicándoselas o poniendo "chantée par Mme. Pauline Viardot", como garantía de calidad, en las portadas o en la primera página de sus canciones. Más aún, la Viardot había conocido en su juventud el sistema de la prima donna assoluta, entre cuyas prerrogativas estaban las de alterar las óperas para realzar su primacía, es decir: suprimir arias de otros cantantes, asumir arias de otros personajes (lo cual podía acarrear adiciones de recitativos que justificasen dramatúrgicamente tal cambio), y adaptar la partitura a sus exigencias vocales. Legalmente, en estos puntos la decisión de la prima donna prevalecía sobre la del autor expresada en la partitura, del mismo modo que su cachet superaba al del compositor más considerado del momento $^{18}$. La experiencia de la Viardot avalaba sus ediciones musicales de autores antiguos. Adviértase que la lógica de su función no era tanto el rescate de una sonoridad antigua (aunque esta finalidad también se contemplaba), como el brindar una aproximación a su propia interpretación, a la sonoridad de la Viardot ${ }^{19}$.

La Viardot era pues una cantante profesional que componía, como tantas antes y después. En palabras de El Segundo Sexo (1949) de Simone de Beauvoir:

en la profesión de actrices, bailarinas o cantantes las mujeres se ganan la vida con la misma independencia que un hombre y encuentran en su trabajo el sentido de la existencia. Además sus éxitos profesionales repercuten en la valoración sexual que se les otorga, de modo que, realizándose como seres humanos, también se realizan como mujeres ${ }^{20}$.

Desde luego, no se dice de una mujer para alabarla que "baila como un hombre" o que "canta como un hombre". Sin embargo, la expresión "compone como un hombre" ha sido históricamente un elogio. Las bailarinas y las cantantes han podido ser, por tanto, profesionales sin renunciar a su feminidad (si bien es obvio que muchas han renunciado a la maternidad). Pero no sucede lo mismo con las

18. Heilbron Ferrer, M. "Isabel Colbran: una soprano española en el mundo de Giochino Rossini". Anuario Musical 55 (2000), p. 181. La prima donna assoluta Colbran cobraba más que Rossini en 1823, cuando el compositor estaba en su apogeo, p. 183.

19. "[Viardot] Chargée de rétrouver et d'indiquer la pensée de ces maîtres elle se sentait portée vers ce travail par les études de toute sa vie, par ses réflexions et ses goûts, par sa pratique journalière de l'art du chant, soit sur la scène, soit dans l'enseignement.

Elle s'est attachée à respecter, et par conséquent à rétablir la pensée originale des maîtres". (Préface des éditeurs, en Händel, Couplets de Suzanne, Oratorio. Traduction de Sylvain St. Etienne. Collection de morceaux choisis dans les chefs d'oeuvre des plus grands maitres classiques italiens, allemands et français avec le style, l'accentuation, le phrasé et les nuances propres à l'interprétation traditionnelle de ces oeuvres par Madame P. Viardot-Garcia. Paris, Ancienne Maison Meissonnier, E. Gérard et Cie Editeurs, s. d. [entre 1867 y 1885] El ejemplar consultado, de la Biblioteca Nacional de Madrid, perteneció a Guelbenzu).

20. Citado en López Pardina, T. "La noción de sujeto en el humanismo existencialista". C. Amorós (ed.), Feminismo y filosofía. Madrid, Síntesis, 2000, p. 208. 
instrumentistas, al menos si se contempla su historia en los últimos siglos. Ellas sí han tenido que tocar "como" los varones. En cualquier caso, a lo largo de los siglos XVIII y XIX en la carrera profesional de mujeres instrumentistas, bailarinas y cantantes observamos, al menos, las siguientes peculiaridades:

- La conciliación. Como les sucede hoy a tantas mujeres con trabajos mal remunerados, a las mujeres con hijos en el siglo XIX solo les era rentable trabajar fuera de casa si eran excelentes. Si eran solo buenas profesionales era mejor quedarse en casa cuidando de los niños ${ }^{21}$. Sabemos que Clara Wieck Schumann (1819-1896), una de las mejores pianistas de todos los tiempos, mantenía en cada viaje al menos dos mujeres de compañía, una para salvaguardar su reputación en los desplazamientos, y otra para cuidar de su marido y de sus hijos, aún cuando sus hijas mayores ya tenían edad para ocuparse de sus hermanos. De hecho, a las instrumentistas de cámara les traía más cuenta casarse con su pareja musical, así no solo se ahorraban las damas de compañía, sino que podían delegar en sus maridos o realizar acompañadas tareas consideradas varoniles: negociar el alquiler de las salas, de la iluminación y de los viajes, la venta de entradas o abonos, y demás labores que entonces realizaban personalmente los intérpretes.

- La dicotomía espacios privados/públicos. Los estudios sobre la historia de las mujeres llevan décadas señalando la importancia de los roles de género en la jerarquía y designación de los espacios privados y públicos. La carrera de Clara Wieck Schumann, de quien se han podido documentar unos dos mil conciertos, ha permitido observar cómo en los salones privados experimentaba con las obras innovadoras, mientras que en las grandes salas tocaba un repertorio más convencional. De esta manera, los musicólogos han tenido que cuestionar su condescendencia hacia los conciertos en ámbitos privados, al imaginarlos como destinados a nobles aburridas y snobs ${ }^{22}$.

A medio camino entre los conciertos privados y los públicos podemos ubicar los cafés teatros y cafés concierto donde se prodigaron orquestas femeninas, especialmente en la última década del XIX y tres primeras décadas del $X X$, antes de que las revistas y teatros de variedades, y enseguida el cine, fueran acabando con estos locales. Aún durante los años 30 y 40 se

21. En los siglos XVIII y XIX era muy alta la probabilidad de que una mujer tuviera hijos menores a su cargo hasta sus últimos años. Por ejemplo, en Francia la esperanza de vida a mediados del XVIII era de 34 años para las mujeres (Wiesner, M-E. Women and Gender in Early Modern Europe. Cambridge, Cambridge University Press, 1993, p. 76). Mientras que en Gran Bretaña era de 44 años en 1890. Entonces una familia europea tenía de media cinco hijos (Anderson, B. S. y Zinsser, J. A History of their own. Women in Europe from Prehistory to the Present. Vol. II. London, Penguin, 1988, pp. 240 y 285).

22. Véase Ellis, K. "Female Pianists and Their Male Critics in Nineteenth-Century Paris". Journal of the American Musicological Society 50, 2-3 (1997). 
prodigaban en Buenos Aires las orquestas de señoritas que tocaban tango y en los EEUU las bandas de jazz femeninas (como recreó la película Con faldas y a lo loco), mientras en Barcelona y Madrid los conjuntos femeninos eran más pequeños ${ }^{23}$.

En Europa estas pequeñas orquestas o grupos de cámara, femeninos o no, tocaban las músicas de moda (tango, fox trot, one step, charlestón, etc.) además de música de cámara de tradición clásica y arreglos de sinfonías, óperas, y operetas, (zarzuelas en España). Muchas veces era la misma agrupación la que interpretaba piezas tan diferentes, variando el repertorio en función del horario y del público, que podía abarcar desde la mamá que merendaba con sus niñas, al marido que alternaba con la amante de turno o a la bohemia. Esta era la música escuchada en provincias, lejos de las grandes orquestas, cuando ya existían la radio y el disco pero aún no tenían la omnipresencia adquirida desde los años 30. Era también el repertorio al alcance de grupos sociales que, aunque vivían en las grandes ciudades, no podían permitirse el acceso a la ópera o a la sala de conciertos. Estas 'orquestas de cafetín', como se les Ilamaba en España (casi siempre un sexteto con piano), también actuaban en las asociaciones obreras, algunas de las cuales eran femeninas ${ }^{24}$.

- La prostitución. Cantantes, bailarinas e instrumentistas han estado asociadas con la prostitución en diferentes culturas y épocas históricas. La asociación entre prostitución y música se ha dado y se da en sociedades asiáticas de distintas religiones, -por ejemplo, en Japón, China y Coreaislámicas y judías, en otros tiempos y ahora. En Occidente han sido particularmente famosas las cortesanas florentinas y venecianas de la época moderna, quienes cultivaban la música y la poesía. En París, las bailarinas del Teatro de la Ópera tenían sus 'protectores', cuyos listados se han conservado $^{25}$. También las bailarinas rusas en tiempos de los zares completaban su reducido salario con obsequios y donativos de sus 'protectores'. Así, el hermano de Ana Karérina (ca. 1871) de Tolstoi, tiene una amante que es bailarina en el Teatro de Ópera. Stefan Zweig compara en sus memorias El mundo de ayer el precio de una bailarina del Teatro de La Ópera de Viena con el de una prostituta de la calle, y con el precio del tabaco. Quizás con-

23. Fleurs Noires es un grupo femenino de tango que se reivindica hoy como 'orquesta de señoritas' en recuerdo de aquellas. Sobre Barcelona, véase Planes, J. M. Nits de Barcelona. Barcelona, Proa, 2001 [1931], p. 170.

24. Véase Valero Abril, P. "La música en los cafés y en las asociaciones obreras: aproximación a un mapa sonoro de Murcia en el primer tercio del siglo XX". P. Ramos López (ed.), Discursos y prácticas musicales nacionalistas. Logroño, Universidad de La Rioja, 2012. p. 333.

25. Véase Brooks, L.M. Women's Work. Making Dance in Europe before 1800. Madison, University of Wisconsin Press, 2007. 
venga recordar que estos casos no pueden considerarse al margen de la explotación social sufrida en el siglo XIX y primeras décadas del XX, cuando la prostitución continuada o esporádica era para muchas mujeres una de las escasas vías de acceso al sustento propio y de sus familias ${ }^{26}$. Un siglo antes, las divas de la ópera veneciana debían someterse a sus protectores, un punto esencial (y diferenciador) en una de las novelas de mayor éxito de George Sand, Consuelo (1843). La obra recrea de manera fascinante (a la vez que documentada) las carreras iniciales de una mezzo, un tenor, y un compositor, los tres de extraordinario talento y extrema pobreza.

A este respecto es necesario recordar la diferencia entre la prostitución -es decir, el intercambio entre placeres sexuales y dinero o regalos- y la independencia económica que permite a la mujer cambiar de pareja. En ocasiones no tenemos datos para poder realizar tal distinción, no sabemos por ejemplo si Barbara Strozzi (1619-1677) era una cortesana. Más complicado sería aún entrar en la naturaleza de relaciones entre personajes tan desiguales como la Giorgina y el virrey de Nápoles, el Duque de Medinaceli ${ }^{27}$. Sin embargo, no siempre se guarda la lógica distancia ante la presunción de prostitución sugerida por una fuente escrita por eclesiásticos, o por autores que tachan de prostituta a cualquier mujer inconstante en sus amoríos. Es lo que sucede en los comentarios sobre las tonadilleras españolas del siglo XVIII, al repetir con sospechosa frecuencia el patrón de La Caramba, de vida alegre en su lozanía y piadoso recogimiento en su madurez. Los sesudos cronistas suelen olvidar que se trata de mujeres que no dependen de ningún varón, y por tanto, se pueden permitir la renovación, un lujo vedado a la mayoría de las mujeres de su tiempo.

- Redes femeninas. Hoy persisten discriminaciones con respecto a las mujeres en las profesiones musicales. Es decir, hay mujeres a las cuales no se les permite realizar actividades para las cuales tienen suficiente preparación y talento. Otras no están dispuestas a sufrir para superar estereotipos de género, de manera que optan por caminos trillados: la docencia, las orquestas de provincia, los atriles secundarios en las primeras orquestas. Por más que busquemos en la música un refugio íntimo frente a los sinsabores cotidianos, ni la creación, ni la distribución, ni la interpretación, ni la recepción de la música pueden abstraerse del contexto social en el cual

26. Por ejemplo, se calcula que en Inglaterra y Gales había unas 30.000 prostitutas en la década de 1850 y 1860. Anderson, B. S. y Zinsser, J. A History of their own. Women in Europe from Prehistory to the Present. Vol. II. London, Penguin, 1988, p. 264.

27. Una interpretación política y cultural de la relación entre el duque y su amante, la cantante, Maddalena Voglia detta Giorgina puede verse en Domínguez, J. M. Roma, Nápoles, Madrid. Mecenazgo musical del duque de Medinaceli, 1687-1710. Kassel, Reichenberger, 2013, pp. 69-74 y 186-189. 
se producen. Conscientes de esas limitaciones, han proliferado redes de mujeres que promueven sus actividades musicales, ya sea en orquestas, plataformas de djs, asociaciones de compositoras o instrumentistas, festivales de música, etcétera.

La escasa profesionalización de las mujeres de otras épocas con talento musical repercute, por otra parte, en la exigüidad y dispersión de las fuentes que testimonian sus actividades musicales, constituyendo una de las principales dificultades para la escritura de una historia anterior a 1900. Hasta bien entrado el siglo XX la mayor parte de las fuentes conservadas informan sobre actividades musicales profesionales y públicas cuyo acceso era restringido para las mujeres: capillas musicales, orquestas, teatros de ópera, escuelas de música, editoriales, etc. En la España de los siglos XVI y XVII, por ejemplo, como una cantante o instrumentista no formaba parte de la 'capilla' o de la 'real cámara', su actividad musical en la corte solo podrá documentarse si aparece en alguna relación de fiestas y representaciones. En los libros de cuentas, su nombre suele quedar registrado únicamente como dama, criada, o menina. Y a veces, solo figura como 'mujer/hija/ o hermana de'. No obstante, las investigaciones han sacado a la luz documentación sobre mujeres que componían, tocaban instrumentos, los construían, encargaban obras musicales, organizaban eventos musicales, enseñaban música, la ejercían profesionalmente, etc.

\section{Otras diferencias}

La profesionalidad no es en definitiva una cualidad que podamos adscribir fácilmente a mujeres de otras épocas de cuya actividad musical tenemos constancia. No es una diferencia exclusiva de las mujeres, claro está. Pero sí es un fenómeno más frecuente en la historia de las mujeres. Consideremos ahora otras peculiaridades, de las cuales me limitaré a exponer algunas ideas generales. Lo que sigue no pretende ser un catálogo exhaustivo de singularidades, sino una mera relación de las más comunes. Como veremos, están a su vez muy relacionadas con la profesionalidad.

\section{La elección de instrumentos y del repertorio}

Los etnomusicólogos han estudiado cómo en distintas culturas el género tiene un papel relevante en la diferenciación de las actividades musicales y en la valoración moral de las mismas. En ocasiones, las mujeres tienen prohibida o restringida a ciertas condiciones la interpretación e incluso la escucha de determinados instrumentos, cantos o danzas, o bien se asocia algunas actividades musicales con la prostitución. En otros lugares, los hombres son considerados afeminados por practicar ciertas músicas. En Occidente, los estereotipos de género siguen pesando cuando los adolescentes escogen un instrumento musi- 
cal ya sea en las bandas de rock $^{28}$ o en los conservatorios ${ }^{29}$. Es más, una mujer ocupando el atril de trompa en la Filarmónica de Berlín sigue siendo una imagen chocante, por lo menos para la gente de cierta edad.

\section{La formación}

El que las mujeres tuvieran vetado el acceso a las capillas musicales de las catedrales, que fueron los principales centros de formación musical durante los siglos XIV al XVIII, supuso que su aprendizaje se realizaba en la familia, como cualquier otro oficio artesanal. Las familias pudientes recurrían a las clases particulares así como aquellas no tan desahogadas pero deseosas tener una hija monja. En los monasterios la música era una necesidad diaria, y por tanto, a las aspirantes con formación musical se les eximía de la obligación de pagar una dote, o al menos se les reducía su importe. Así, la institución ganaba una instrumentista o una cantante, y a veces ambas cosas. La contrapartida era que estas religiosas solían ser tratadas como criadas dentro del convento, pues en la España de la época moderna, como sucedió también en la América hispana, la música era un oficio humilde.

Italia era un caso excepcional, puesto que allí, en el país que durante la Edad Moderna exportó música y músicos a todo el mundo, desde el siglo XVI los conservatorios facilitaron el que mujeres instrumentistas y compositoras accedieran a una carrera profesional ${ }^{30}$. Los conservatorios inaugurados en el resto de Europa tras la Revolución Francesa siempre admitieron a las mujeres, pero en clases diferentes a los varones y no en todas las materias.

\section{El cultivo doméstico de la música}

Pese a que se trata de una actividad no profesional, también aquí existen diferencias pronunciadas entre las prácticas femeninas y las masculinas, según las épocas y según los países. Y pondré un ejemplo quizás poco conocido: la práctica inexistencia de representaciones de mujeres haciendo música en la pintura española de los siglos XVI y XVII. A diferencia de lo que ocurre en Italia, Francia, Gran Bretaña o los Países Bajos, en España las escenas musicales con mujeres cantando o tocando instrumentos no constituyeron un género pictórico. Las mujeres hacían música en casa, pero no se retrataban con instrumentos ni can-

28. Green, L. Música, Género y Educación. Madrid, Morata, 2001 [1997].

29. Ravet, H. "Professionnalisation féminine et féminisation d'une profession: les artistes interprètes de musique". Travail, Genre et societés 9 (2003). 1993.

30. Baldauf-Berdes, J. Women Musicians of Venice 1525-1855. Oxford, Clarendon Press, 
tando. Muy posiblemente, la razón se halle en la estricta moralidad de los tratados de conducta ibéricos ${ }^{31}$.

Por cierto que la consideración del hogar como un espacio de recepción y consumo musical puede llevarnos a cuestionar conclusiones un tanto apresuradas de estudiosas feministas. Por ejemplo, la consideración de la sonata clásica, la estructura predominante en la música instrumental de las dos últimas décadas del XVIII y de gran parte del XIX, como masculina, en tanto que privilegia en la composición la racionalidad y lo orgánico ${ }^{32}$. Ciertamente, la sonata no ha sido una de las formas favoritas entre las compositoras de esa época. Sin embargo, Haydn, Mozart y Beethoven escribieron sus sonatas sabiendo que la mayor parte de sus intérpretes eran mujeres, como reconoce el propio Charles Rosen ${ }^{33}$. Por tanto, desde el punto de vista de la historia de las mujeres, e incluso desde el punto de vista de una historia de la música que ya no es una mera historia de la composición, es insostenible la sonata como un género 'masculino'.

\section{La ansiedad de la creación y el problema de la autopromoción}

Toca ahora mencionar al menos un problema compartido por muchas mujeres que han abordado la composición, ya sea de manera profesional o no. Se trata de la Ilamada "ansiedad de la creación", que podríamos resumir como el resultado de la interiorización o consciencia por parte de las mujeres de no insertarse en una tradición o genealogía de compositoras ${ }^{34}$. Las intérpretes no tenían este problema, pues nunca se perdió la memoria de cantantes e instrumentistas. Sin embargo, compartían con las compositoras, y en general, con las escritoras o pintoras, el problema de que la autopromoción -necesaria en la carrera de cualquier artista, ya sea en un sistema de mecenazgo o en una sociedad de mercado- se ha juzgado como inapropiada para las mujeres ${ }^{35}$.

31. En especial, con las ediciones españolas de la Institutio Feminae christianae de Juan Luis Vives (1524). Ramos López, P. "Musical practice and idleness: a moral controversy in Renaissance Spain". Acta Musicologica 81 (2009), 255-274 y Ramos López, P. "The Spanish Prohibition on Women listening to music: some reflections on Juan Luis Vives and the Jewish and Muslim Legacy". Recent Research on Early Iberian Music in an International Context, T. Kighton y E. Ros-Fábregas (eds.). Kassel, Reichenberger, en prensa.

32. Citron, M. Gender and the Musical Canon. Cambridge, Cambridge University Press, 1993, p. 24.

33. Rosen, Ch. El estilo clásico: Haydn, Mozart y Beethoven. Madrid, Alianza, 1986, p. 54.

34. El concepto fue acuñado por Sandra Gilbert y Susan Gubar en su estudio sobre las escritoras anglófonas del siglo XIX, como contraposición al concepto de "ansiedad de la influencia" de Harold Bloom. Véase Gilbert, S. y Gubar, S. La loca del desván: la escritora y la imaginación literaria del siglo XIX. Madrid, Cátedra, 1998 [1979].

35. Wiesner, M-E. Women and Gender in Early Modern Europe. Cambridge, Cambridge University Press, 1993, p. 150. 


\section{Conclusiones}

Hemos visto ciertas peculiaridades en la historia de las actividades musicales de las mujeres occidentales que atañen a la profesionalidad, la elección de instrumentos y el repertorio, la formación, el cultivo doméstico de la música, la ansiedad de la creación y el problema de la autopromoción. A pesar de que todas estas cuestiones son relevantes en la historia de las mujeres compositoras, intérpretes, mecenas o consumidoras de música, suelen ser obviadas en estudios recientes, al dar por supuestas unas condiciones similares a las de los varones contemporáneos. Las diferencias exigen un tratamiento historiográfico sensible a las mismas, lo cual implica conocer las investigaciones sobre la historia de las mujeres. Ya en uno de los textos pioneros de la musicología feminista, Eva Rieger incidía en cómo las mujeres habían contribuido de manera diferente a los hombres a las diversas ramas de la música ${ }^{36}$. En Occidente estas actividades nunca fueron realizadas por las mujeres 'al igual que' por los hombres. La diferencia en el objeto de estudio exige una diferencia en nuestra investigación.

Tras varias décadas de estudios sobre las mujeres, los musicólogos seguimos topando con el problema de la escasez y la dispersión de las fuentes que nos informen de su historia. Por ello, se hace especialmente necesario un adecuado bagaje teórico y metodológico que permita exprimir las fuentes disponibles. Cuando se trabaja sobre la historia de las mujeres sin marco teórico y sin una contextualización (que relacione el dato con la historia de las mujeres) se desemboca en un anecdotario, reduciendo a historieta lo que quizás tenía un impulso reivindicativo respecto al papel de las mujeres en la historia. En definitiva, no puede escribirse sobre la historia musical de las mujeres al margen de la historia de las mujeres.

36. Rieger, E. “¿'Dolce semplice'? El papel de las mujeres en la música”, G. Ecker (ed.), Estética feminista. Barcelona, Icària, 1986, p. 175. 